\title{
SOFTWARE LIVRE COMO ALTERNATIVA DE INOVAÇÃO NA GESTÃO DOS SERVIÇOS DE BIBLIOTECA: A EXPERIÊNCIA DO NIB DO CBPF
}

\author{
OPEN-SOURCE SOFTWARE AS AN INNOVATION \\ ALTERNATIVE IN THE MANAGEMENT OF LIBRARY \\ SERVICES: THE NIB EXPERIENCE AT CBPF
}

\author{
Fátima Santana da Silvaa \\ Heloísa Maria Ottonib \\ Rita Miryam Leme Silvac
}

\begin{abstract}
RESUMO
Introdução: Discute-se a utilização de software livre como alternativa de inovação na gestão dos serviços de biblioteca. É resultado de uma das etapas de trabalho da equipe do NIB. Apresenta-se um breve estudo teórico sobre a aplicabilidade dos softwares proprietário e livre em bibliotecas e o resultado de pesquisa exploratória. Objetivo: Investigar tanto o desempenho do sistema de gestão de informação das bases de dados da biblioteca do NIB, hoje o sistema proprietário Pergamum, quanto o padrão de satisfação de bibliotecas com seus sistemas de gestão de informação. A motivação foi identificar um sistema que oferecesse mais autonomia que o atual, de modo que seja possível adequá-lo às necessidades emergentes da comunidade da física. Metodologia: Foram desenvolvidos dois tipos de pesquisa, uma teórica sobre software livre e proprietário e outra exploratória para esclarecer sobre a utilização de SIGB em bibliotecas brasileiras. Dados foram levantados a partir de pesquisa na literatura, contatos informais e aplicação de questionário. Resultados: Surge a opção de solução open-source, apesar de sistemas proprietários terem 100\% de aceitação entre clientes, com algumas ressalvas. Os três sistemas free mais bem avaliados foram: Koha (26,2\%), BibLivre e PHL (21,05\%, ambos). Conclusões: Estudos feitos pelo NIB a partir de 2019 apontam que o sistema Koha atenderia às necessidades de inovação na gestão dos serviços da biblioteca. A próxima etapa de trabalho do NIB prevê a criação de bases de dados de teste para viabilizar a implantação do Koha e procedimentos operacionais para garantir a segurança à possível migração dos dados.
\end{abstract}

Descritores: Serviços de biblioteca. Automação de biblioteca. Programas livres

\footnotetext{
a Mestre em Ciência da Informação pela Universidade Fderal do Rio de Janeiro (IBICT/UFRJ) . E-mail: fatimasilva@cbpf.br

b Doutor em Ciência da Informação pela Universidade Fderal do Rio de Janeiro (IBICT/UFRJ). Analista de informação em C\&T - CBPF/NIB. E-mail: hottoni@cbpf.br

c Bibliotecário pela UNIRIO. Analista de informação em C\&T - CBPF/NIB. E-mail: rita@cbpf.br.
} 
Programas proprietário.

\section{INTRODUÇÃO}

Diante do atual cenário em que o livro impresso deixa de ser o ator principal, a instituição biblioteca, para se adequar aos novos tempos das Tecnologias da Informação e Comunicação precisa se reinventar, criar novos serviços, novas formas de acesso à informação, ambientes atrativos e democráticos que promovam com mais efetividade a geração de conhecimento.

A biblioteca do Centro Brasileiro de Pesquisas Físicas (CBPF), atuante desde 1949, vem buscando construir novas estratégias de ação, com a meta de atualizar e aperfeiçoar seu perfil de atendimento à comunidade da física, utilizando novas tecnologias em produtos e serviços.

O Núcleo de Informação C\&T e Biblioteca (NIB), criado em 2018, tem como parte de sua missão integrar a biblioteca do CBPF num novo ambiente de oferta de conhecimento científico e tecnológico, ágil, diversificado e contextualizado, importante para a sua comunidade. As iniciativas desenvolvidas pelo NIB privilegiam o usuário e suas necessidades informacionais, acima de sua função tradicional de tratamento técnico, guarda e manutenção do acervo. Hoje, a missão é facilitar o acesso, independentemente do suporte em que a informação esteja inserida.

Sales e Sayão (2015) afirmam que as mudanças nos paradigmas da ciência e no modelo de comunicação científica geram um descompasso entre a biblioteca e os pesquisadores. Diante deste cenário, surge a questão: O que se precisa oferecer de recursos informacionais numa biblioteca para caminhar junto com o desenvolvimento da ciência? Em busca de respostas, optou-se por realizar um estudo em busca de possibilidades mais eficazes que possam contribuir com os serviços oferecidos no NIB, atualmente.

Esse estudo vem sendo desenvolvido em etapas, buscando consolidar os resultados alcançados regularmente, e assim diminuir os obstáculos a serem vencidos nas etapas seguintes. O objetivo geral é aproximar continuamente 0 NIB de seus clientes. A primeira etapa para atender a esse objetivo vem sendo 
desenvolvida, que é avaliar o estado-da-arte do NIB e estudar as possibilidades de melhorar a prestação de serviços, a partir de seu sistema da gestão de informação da biblioteca.

Sistemas Integrados de Gestão de Bibliotecas (SIGB) são úteis por relacionar os bancos de dados de informações geradas para criar produtos $\mathrm{e}$ serviços em bibliotecas. O SIGB do NIB, atualmente, tem impossibilitado a implantação de inovações almejadas. Questões administrativas e tecnológicas, objetivando autonomia e agilidade para a biblioteca do NIB, não vem sendo sanadas em nível desejável pela empresa fornecedora do software. Ao longo dos últimos dois anos, o suporte virtual oferecido muitas vezes tem desempenho ineficaz para as metas do NIB. Diante deste cenário, iniciou-se um estudo para identificar se existem soluções open access que atendam às necessidades da biblioteca do NIB e que possam resolver essas questões.

Esse artigo informa sobre o resultado de uma pesquisa exploratória desenvolvida na primeira etapa do processo de integração da biblioteca do CBPF ao NIB, com a intenção de conhecer o padrão de satisfação de bibliotecas, com relação aos sistemas de informação que utilizam. A partir de então, procurar conhecer a realidade de usos desses sistemas, em busca de alcançar novas e melhores possibilidades de atender às necessidades da comunidade científica da física.

\section{METODOLOGIA ADOTADA}

Foram desenvolvidas pesquisas, teórica e exploratória, para esclarecer sobre a utilização de SIGB em bibliotecas brasileiras. Assim sendo, o levantamento dos dados se baseou em pesquisa na literatura, contatos informais e aplicação de questionário

\subsection{Pesquisa Teórica}

Foi identificado na literatura relatos de experiência referentes à utilização de softwares proprietário e livre na gestão dos serviços de bibliotecas e aspectos conceituais voltados a sistemas de informação. 
A pesquisa teórica teve suas bases de estudo principalmente em artigos científicos, dentre eles se destacam: Café, Santos e Macedo (2001), que trazem uma proposta para escolha de software para bibliotecas; Viana (2016) com uma breve história de automação de bibliotecas no Brasil; Oliveira (2010) que relata os fatores que influenciam a adoção de software livre por instituições públicas, entre outros, com o objetivo de levantar informação sobre a importância da geração de conhecimento entre usuários de biblioteca e as facilidades que seus produtos e serviços de informação podem oferecer.

\subsection{PeSquisa EXPLORATÓRIA}

Realizou-se uma pesquisa exploratória quali-quantitativa por amostragem, em função de localidade e disponibilidade de contato. O conteúdo do questionário foi dividido em duas partes.

$\mathrm{Na}$ primeira parte com clientes do Sistema Pergamum alocados nas cidades do Rio de Janeiro e de São Paulo, priorizando os que possuíam contato de e-mail institucional. $O$ objetivo foi identificar se as instituições estariam satisfeitas com os serviços oferecidos e se os recursos de seu sistema atendiam às necessidades se sua clientela.

Na segunda parte, entre usuários de sistemas open-source, selecionouse nas páginas dos diversos softwares uma amostra de clientes, somente aqueles que tinham seus e-mails ativos. Buscou-se saber a opinião dos utilizadores, quanto ao funcionamento do sistema que adotam, a gestão de recursos eletrônicos, processo de migração, padrão de satisfação e se indicariam outro software para a instituição ao qual estão vinculados.

A pesquisa foi realizada entre os meses de julho e agosto de $2019 \mathrm{com}$ 27 encaminhamentos e 14 respondentes na primeira parte e 36 encaminhamentos na segunda parte, destes, 19 respondentes.

Um modelo de questionário semi-estruturado (APÊNDICES A e B), foi aplicado nestas instituições, utilizando a plataforma Survey Monkey ${ }^{1}$, visando

\footnotetext{
1 Survey Monkey é um software de desenvolvimento de pesquisas online, que provê pesquisas personalizáveis gratuitas, bem como uma suíte de programas back-end que inclui análise de dados, seleção de amostras, eliminação de vieses, e ferramentas de representação de dados. (How to Use Online Tools for Customer Surveys. Disponível em:
} 
esclarecer sobre o uso e as facilidades oferecidas pelos softwares de bibliotecas, da implantação à divulgação de informação de suas bases de dados.

Foram feitos também alguns contatos informais que permitiram esclarecer sobre informações técnicas com utilizadores de SIGBs, para ampliar conhecimento sobre as experiências vivenciadas e enriquecer o conteúdo do artigo.

\subsection{Consolidação dos Resultados de Pesquisa}

O resultado das duas partes da pesquisa exploratória realizada foi discutido com toda a equipe do NIB. Foi feita uma avaliação conjunta e multidisciplinar desses resultados entre profissionais: bibliotecário, técnico de biblioteca e de tecnologia da informação (TI).

Ressalta-se que a pesquisa teórica e exploratória, agregada à prática profissional da equipe do NIB, resultou na escolha do software considerado mais adequado às necessidades tecnológicas e operacionais da biblioteca do NIB neste momento. A equipe já estuda sobre a migração do sistema proprietário Pergamum, atualmente adotado no NIB, para o de software livre.

\section{SOFTWARE PROPRIETÁRIO COMO REALIDADE BRASILEIRA EM GESTÃO DOS SERVIÇOS DE BIBLIOTECA}

O software proprietário (SPp) sobre sistemas integrados de bibliotecas segundo Viana (2016) começaram a ser adotados no Brasil a partir da década de 90. Nesta década algumas bibliotecas começam a adquirir sistemas estrangeiros, um dos primeiros sistemas adotados foi o Sistema Aleph pela Pontifícia Universidade Católica do Rio Grande do Sul (PUCRS). O segundo sistema destacado foi o sistema Virtua, utilizado pela Universidade Federal de Minas Gerais em 1996. Paralelamente a esta importação de softwares, empresas brasileiras começam a ser criadas e logo passam a disponibilizar opções nacionais como: Ortodocs (1986), Pergamum (1997) Sysbibli (1990),

<https://www.inc.com/guides/2010/07/how-to-use-online-tools-for-customer-surveys.html>. Acesso em 08 abr. 2020.) 
CARIBE Biblioteca (1995), SophiA Biblioteca (1993), entre outros. (VIANA, 2016)

As empresas produtoras, além do software, passaram a oferecer serviços pagos de assistência/manutenção anual a seus sistemas, o que vem representando facilidades para seus operadores, principalmente em bibliotecas que não têm assistência efetiva de profissionais de informática e quando os usuários destes softwares não têm familiaridade com os recursos de gestão integrada de base de dados. Estes serviços contemplam apoio à catalogação, atividades de controle de circulação do acervo e de usuários, geração de relatórios de gestão dos sistemas, suporte de informática ao funcionamento do sistema e atualização de novas versões.

De uma maneira geral, um SPp, muitas vezes anda em descompasso com as necessidades de seus clientes. De acordo com Silveira:

O modelo de software proprietário esconde os algoritmos que o compõem. Apesar de ser composto por informações agrupadas e de se basear em conhecimentos acumulados pela humanidade, a indústria de software proprietário se direcionou para tentar bloquear e evitar que o caminho de seu desenvolvimento fosse semelhante ao desenvolvimento do conhecimento científico. A ciência cresce a partir do princípio de compartilhamento, e não a partir da ideia de propriedade. Por ser essencialmente social, não se aplica ao conhecimento a ideia de apropriação privada. (SILVEIRA, 2004, p. 10)

Esses sistemas proprietários vêm fazendo esforço de acompanhar o perfil de necessidade de sua clientela e entre os principais fornecedores desses produtos tem havido progresso em novas facilidades e incremento de serviços. $O$ resultado da pesquisa, apresentado a seguir, confirma esta afirmação. A expectativa é que a performance operacional desses sistemas proprietários, atendam às particularidades de sua clientela, no dia-a-dia de suas operações. Que o investimento financeiro represente facilidades e agilidade na gestão e na disseminação de informação, atendendo às particularidades de cada biblioteca e de sua clientela.

\subsection{A Utilização de Software Proprietário na Biblioteca do NIB}

O sistema Pergamum iniciou suas atividades em 1997 e foi contratado pelo CBPF em 2005 para cumprir as rotinas de gerenciamento da informação 
produzida pela biblioteca do CBPF e de ampliação de possibilidades de prestação de seus serviços. Este sistema de gerenciamento de bases de dados para bibliotecas, o Pergamum, é comercializado entre instituições de perfis variados e na atualidade presta serviço a aproximadamente 600 instituições em todo o Brasil. Por ser um sistema que integra atividades técnicas de biblioteca, ele oferece a vantagem de agregar informações sobre as fontes do acervo à dinâmica de sua utilização por consultas, empréstimos, renovação, reservas, histórico de uso, entre outros serviços oferecidos.

É importante salientar que uma das principais funcionalidades de um sistema integrado de bibliotecas é qualificar as atividades de gestão, de disseminação e de controle de acervos. E a expectativa da biblioteca do CBPF com a aquisição do Sistema Pergamum foi facilitar o processo de administração e de gestão de informações da biblioteca, hoje com um acervo de aproximadamente 26 mil exemplares sobre física e ciências afins, entre livros, folhetos, teses e dissertações, monografias diversas e cerca de 850 títulos de periódicos, muitos deste em edição centenária.

Atualmente o Sistema Pergamum é utilizado no CBPF por bibliotecários (catalogadores/classificadores/indexadores e de referência), junto a auxiliares (atendimento ao público, alunos).

\subsection{A Utilização do Sistema Pergamum em Algumas Bibliotecas Brasileiras}

O item trata dos principais resultados da primeira parte da pesquisa feita pelo NIB, que buscou identificar o grau de satisfação dos clientes com o uso do sistema Pergamum e de perceber se há insatisfações quanto aos serviços oferecidos, conhecendo as necessidades não atendidas.

A maioria (71\%) dessas bibliotecas utiliza o Sistema Pergamum há mais de acima de 5 anos e todas elas (100\%) declararam estarem satisfeitas com os serviços oferecidos por esse sistema.

Mesmo com os $100 \%$ de aprovação desses respondentes, em questão aberta no questionário, $1 / 3$ deles mencionou sobre a necessidade de melhorias nas opções disponíveis no módulo "relatórios" do Sistema. Mencionou-se 
também sobre a importância da interoperabilidade do Sistema Pergamum com outros sistemas, bases e repositórios do interesse de suas comunidades de pesquisa.

Quanto à necessidade de melhorias, foram relatadas algumas iniciativas que podem ser aperfeiçoadas nos serviços oferecidos pelo Sistema Pergamum, com destaque a:

1) relatórios internos do sistema, que poderiam ser mais adaptáveis à necessidade de cada usuário;

2) O OPAC (online public access catalog) poderia ser mais amigável, interativo e personalizado a cada biblioteca;

3) os manuais de orientação ao uso dos módulos do sistema poderiam estar mais acessíveis, possivelmente em hiperlinks nos sistemas de cada biblioteca e dentro de cada módulo de uso, para agilizar as consultas;

4) a importação de dados poderia ser mais simplificada e didática, concentrando e/ou reduzindo passos do processo.

Além desses destaques, o NIB do CBPF ainda contribui, acrescentando as ações de melhoria:

5) a expansão de caracteres especiais do sistema, útil incluir em hiperlinks: simbologia matemática e suas funções e outros alfabetos além do latino, como o grego, muito utilizado em bibliotecas especializadas, e ainda o russo, o romeno.

6) ampliar opções para saída de pesquisas bibliográficas, atualmente somente pela ABNT; poderia dar opção ao cliente de usar o padrão Vancouver.

Apesar dessas necessidades de melhoria indicada nas questões abertas da pesquisa, a maioria dos respondentes (92,86\%), usuários do Sistema Pergamum, não indicaria outro software de gestão de bibliotecas para sua instituição, além do Pergamum. (Gráfico 1)

Mesmo com a unanimidade no padrão de satisfação com o sistema Pergamum entre os respondentes da pesquisa, percebeu-se que nas questões 
abertas existe um percentual (7,14\%) que ainda assim identifica problemas e sugere outro SPp como opção.

\section{Gráfico 1 - Adesão ao Sistema Pergamum (92,86\%)}

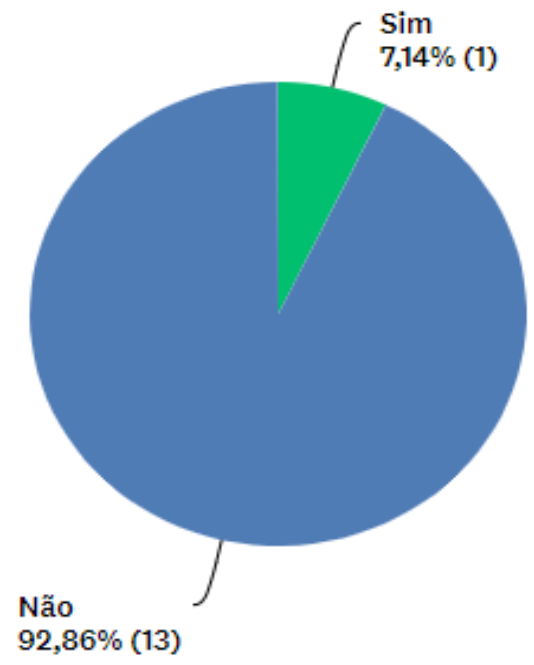

Fonte: Pesquisa exploratória realizada pelos autores - jul. /ago. 2019

A tendência é que este conflito de informações (100\% satisfeitos $X 7,14 \%$ com ressalvas) se justifique pelo fato de que nenhum sistema é perfeito. Sempre vai haver necessidades não atendidas e melhorias a serem feitas; isso porque a dinâmica de geração e de uso da informação vem sofrendo alteração constantemente para acompanhar as necessidades da clientela. De forma geral, o software Pergamum possui uma ótima aceitação no mercado.

Com base nestas informações fica claro que a busca por mudanças na biblioteca do NIB é baseada em outras questões que vão além da qualidade dos serviços de um software proprietário de qualidade. O NIB busca a liberdade de escolha e decisão, onde a agilidade de respostas e a customização permanente de seus produtos e serviços são essenciais.

\section{USO DE SOFTWARE LIVRE COMO POSSIBILIDADE DE INOVAÇÃO EM BIBLIOTECAS}

O software livre (SLv) tende a ser uma alternativa muito promissora para uso em bibliotecas na atualidade. Há a expectativa de fortalecimento de suas 
redes de colaboração profissional e de sustentabilidade de suas iniciativas, ampliando as possibilidades de qualidade na oferta de produtos e serviços de informação. Sobre software livre, Silveira (2004, p. 11) afirma que:

O software livre possui um autor ou vários autores, mas não possui donos. Dessa forma, o usuário do software livre também tem o direito de ser desenvolvedor, caso queira. Quem o adquire pode usá-lo para todo e qualquer fim, inclusive tem a permissão de alterá-lo completamente. Assim, para um software ser efetivamente livre deve necessariamente disponibilizar seu código-fonte. A única proibição feita aos seus usuários é a de torná-lo um software proprietário.

As ações de colaboração é que sustentam a estrutura de geração de tecnologia, onde se tem "o modelo de código aberto [...] colaborativo que envolve programadores da empresa e todos aqueles interessados no desenvolvimento daquele software, inclusive voluntários espalhados pelo mundo" (SILVEIRA, 2004 , p. 12). Lima e Santini resumem o assunto quando afirmam que "a grande inovação no desenvolvimento dos softwares livres está na organização do trabalho em rede aberta (LIMA, SANTINI, 2008, p. 106)

A flexibilidade gerada pelo código aberto permite que as "instituições adaptem o software às suas necessidades, oferecendo uma via para um serviço gerir, independentemente, os seus próprios dados e sistemas" (ALMEIDA, 2009, p. 51). Esta afirmação vai ao encontro das necessidades emergentes de gestão dos serviços de biblioteca, em busca de aprimoramento em seus processos de trabalho no contexto das necessidades de informação de seus usuários. Neste sentido, autonomia, liberdade e atuação cooperativa com criatividade e inovação são os fundamentos do processo de aprimoramento desses serviços. Lima e Santini complementam esse ponto de vista, quando afirmam que:

A questão é o que se pode fazer por um mundo onde todos trabalhem em cooperação, usando ou não as novas tecnologias de informação e comunicação, na solução de problemas e na criação de melhores formas de organização e de produção. (LIMA, SANTINI, 2008, p. 108) 
Normalmente, um SLv tende a adotar o código aberto². Com foco em destacar a produtividade de softwares, Carrez (2019) menciona cinco vantagens que podem atrair bibliotecas nesta direção de adoção de um software de código aberto. Destaca ele: disponibilidade de acesso sem barreiras ao teste e uso de suas funcionalidades; sustentabilidade, o que significa inexistência de restrições de fornecedores; independência nas ações de manutenção, desde que haja profissional de TI na equipe; atração de talentos interessados em desenvolver e aperfeiçoar seus projetos, expandindo as funcionalidades do software aos demais usuários; transparência de acesso ao código-fonte para aprimoramento do software; contribuição direta ao software, onde o interessante é que os concorrentes colaborarem entre si, criando alternativas de melhoria ao sistema, desvinculados de um dado fornecedor.

Complementando essas vantagens, o Projeto $\mathrm{GNU}^{3}$, patrocinado pela Free Software Foundation, possui como filosofia quatro liberdades neste ambiente de trabalho, "do contrário não pode ser considerado livre". As liberdades de:

1) executar o programa como você desejar, para qualquer propósito;

2) estudar como o programa funciona, e adaptá-lo às suas necessidades. Para tanto, acesso ao código-fonte é um pré-requisito;

3) redistribuir cópias de modo que você possa ajudar outros, e

4) distribuir cópias de suas versões modificadas a outros. Tendo o código-fonte liberado, dá-se oportunidade de toda uma comunidade se beneficiar com suas mudanças.

É importante saber que existem software de código aberto que não asseguram essas quatro liberdades (SILVEIRA, 2004). Por isso é importante,

\footnotetext{
${ }^{2}$ Código aberto (open-source) diz respeito à liberação do código-fonte de um software, que pode ser adaptado para diferentes fins sem custo de licença. Na grande maioria dos casos, essas ferramentas são compartilhadas online pelos desenvolvedores, podendo ter acesso a elas qualquer pessoa, sem restrições. Mais detalhes em: https://canaltech.com.br/produtos/O-quee-open-source. Acesso em 16 abr. 2020.

3 O Projeto GNU foi concebido em 1983 como uma maneira de trazer de volta o espírito cooperativo que prevalece na comunidade de computação nos seus primórdios - para tornar a cooperação possível novamente ao remover os obstáculos à cooperação impostos pelos donos de software proprietário. (https://www.gnu.org/gnu/gnu-history.html. Acesso em 14 abril 2020).
} 
para os profissionais de biblioteconomia, entenderem a distinção básica e geral entre as categorias de software, que entre outros sites, pode ser consultado em $<$ https://www.infowester.com/freexopen.php>. Acesso em: 17 abr. 2019, que distingue da seguinte forma: software de código aberto (open-source) disponível para download por qualquer pessoa, prevendo-se a colaboração entre desenvolvedores; software gratuito (freeware) utiliza-se sem pagar, porém, só o autor ou a entidade que o desenvolve tem acesso ao código-fonte; e software livre (free software), que dá a liberdade ao usuário para utilizar, copiar, distribuir, modificar e estudar o software. Oliveira (2010) ressalta que a principal questão relativa ao software livre é a luta pela liberdade de conhecimento e liberdade de escolha.

Vale destacar a Instrução Normativa n4, de 11 de setembro de 2014 que "Dispõe sobre o processo de contratação de Soluções de TI pelos órgãos integrantes do Sistema de Administração de Recursos de Tecnologia da Informação e Informática (SISP) do Poder Executivo Federal". Os órgãos abraçaram a causa e, atualmente, seguem a instrução com um bom nível de maturidade. O sucesso é tanto que há um movimento no Governo Federal para a elaboração de uma Instrução Normativa com fases, etapas e artefatos semelhantes para aquisições de bens e serviços em geral, não englobando apenas Tecnologia da Informação (TI). No caso específico de softwares livres para bibliotecas, tomamos como base o Art. 12 que cita "a capacidade e alternativas do mercado, inclusive a existência de software livre ou software público".

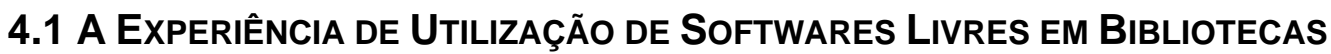 BRASILEIRAS}

Este item apresenta o resultado da pesquisa exploratória que buscou investigar sobre os SLvs adotados nas bibliotecas. O conteúdo do item informa sobre o que motivou a preferência por SLv ao SPp, como foi o processo de migração do sistema de origem, se a biblioteca possui uma equipe de $\mathrm{TI}$, sobre a gestão dos e-books do acervo e também saber sobre a satisfação com os serviços. 
Nos sistemas adotados nas bibliotecas, tivemos o seguinte percentual de resposta: Koha com $26,32 \%$, vindo a seguir o Bibilivre e o $\mathrm{PHL}$, com o mesmo percentual $(21,05 \%)$. Porém, vale registrar que um grupo de mais de $1 / 4$ das bibliotecas pesquisadas usa sistemas variados e que individualmente têm uma representatividade de 5,3\% em média, percentual considerado inexpressivo no âmbito desta pesquisa. O GRÁFICO 2 apresenta esse resultado geral.

\section{Gráfico 2 - Software Livre em Bibliotecas Especializadas Brasileiras}

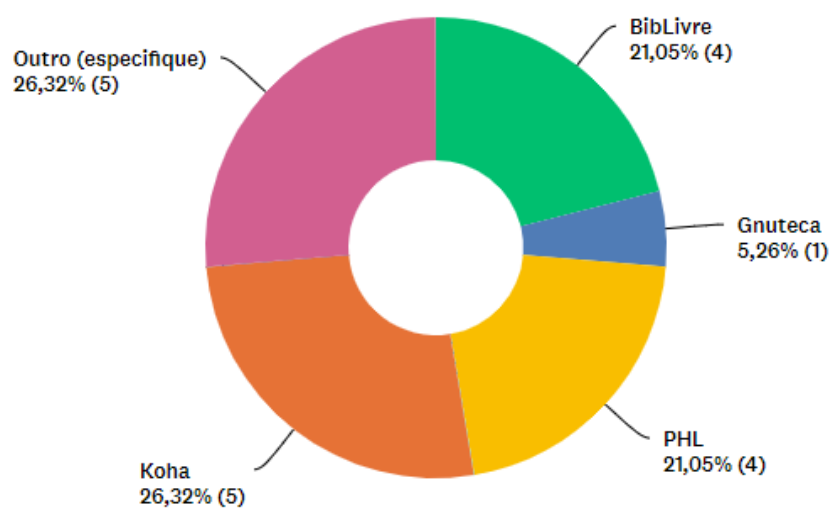

Fonte: Pesquisa exploratória realizada pelos autores - jul. /ago. 2019

A maioria das bibliotecas $(73,68 \%)$ optou por adotar um software livre mais pelos recursos oferecidos do que por sua gratuidade (vide GRÁFICO 3). Este resultado expõe a tendência de que as bibliotecas estão buscando criar seus próprios espaços de gestão da informação. Elas estão aceitando a responsabilidade de participar da implementação e da criação de suas plataformas de informação para produtos e serviços, demonstrando também que o perfil profissional do bibliotecário tem se intensificado de novas TICs. Essa tendência de qualificação profissional parece corroborada pelo fato das bibliotecas pesquisadas se motivarem ao uso dos SLvs, muito mais pelos recursos de tecnologia e nas funcionalidades oferecidas $(73,68 \%)$ do que por sua gratuidade $(26,32 \%)$.

A maioria das bibliotecas considerou o processo de migração de média complexidade (50\%), apesar de $31,25 \%$ do total ter considerado a migração um processo complexo. Apenas $18,75 \%$ entendeu essa migração como um 
processo simples. (Vide GRÁFICO 3).

Mesmo com o grau de complexidade pelo qual passaram as bibliotecas nos processos de migração, apenas $22,22 \%$ delas tem pessoal de $\mathrm{Tl}$ em sua equipe. Resultado que chama a atenção mais uma vez de que o profissional bibliotecário tem ampliado sua capacidade de trabalho para a solução de seus problemas de gestão da informação. Acredita-se que a comunicação em rede de usuários dos SLv tenha sido um elemento facilitador neste processo de migração.

\section{Gráfico 3 - Grau de Complexidade do Processo de Migração de SPp para SLv}

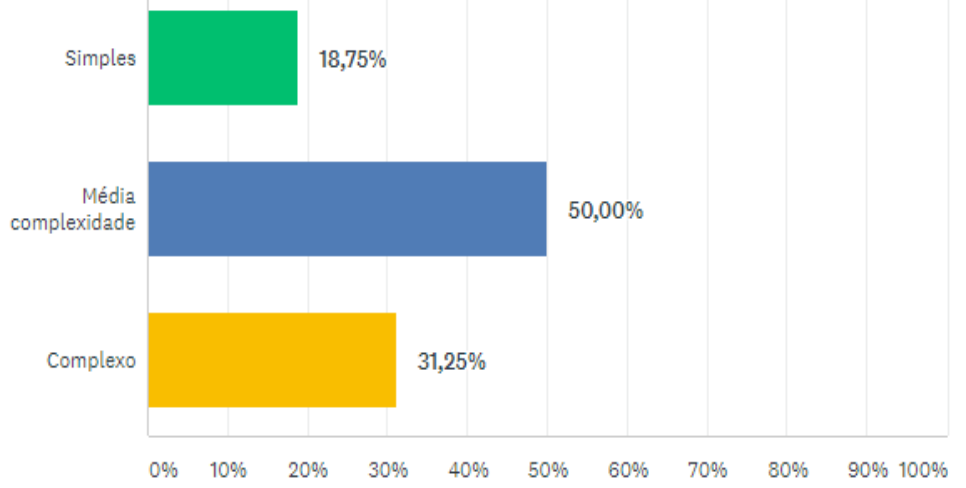

Fonte: Pesquisa exploratória realizada pelos autores - jul. /ago. 2019

Quanto ao funcionamento pós-instalação destes SLvs, a pesquisa detectou que até aquele momento não havia resultado insatisfatório de uso. Um percentual de $52,63 \%$ de usuários está satisfeito e, positivamente, 47,37 considerou o desempenho de seu SLv excelente (vide GRÁFICO 4). Da totalidade de recursos oferecidos pelos SLvs, a pesquisa detectou que $82,35 \%$ deles são utilizados regularmente nas bibliotecas. Esse resultado de desempenho tende a ser animador para as bibliotecas que estejam pensando em adotar um SLv.

A grande maioria $(70,59 \%)$ dessas bibliotecas não possui e-books, apesar de a quase metade $(42,86 \%)$ dos SLvs utilizados oferecerem recursos para a gestão de e-books. Este resultado parece curioso e motivador para aprofundamento de pesquisa, uma vez que e-journals e e-books já vem sendo usados há pelo menos uns cinco anos entre os usuários de bibliotecas. 


\section{Gráfico 4 - Padrão de Satisfação com o Uso de SLv em Bibliotecas Especializadas}

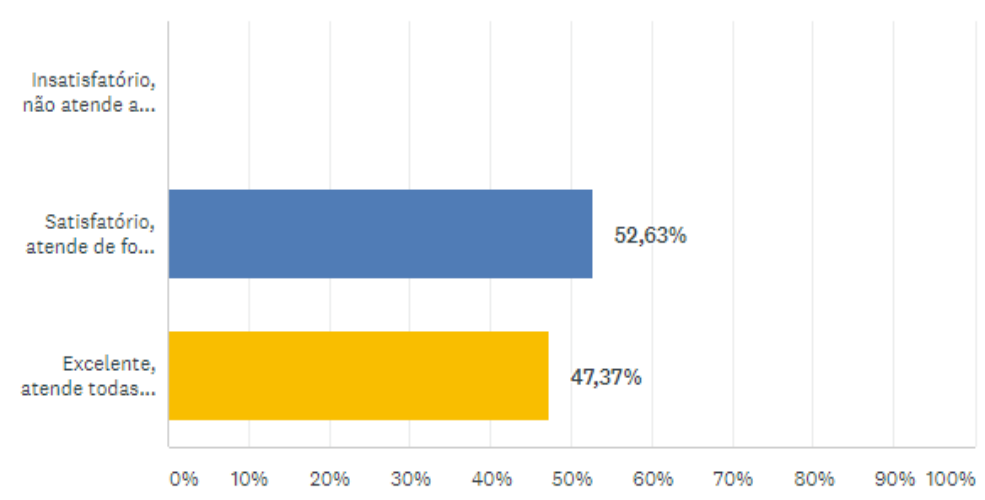

Fonte: Pesquisa exploratória realizada pelos autores - jul. /ago.

Outro dado curioso da pesquisa é que $50 \%$ das bibliotecas que já usam o SLv indicariam outro software para sua instituição, mesmo com um percentual nulo de insatisfação de uso detectada na pesquisa. $O$ que se supõe que tenha ocorrido é que algum dos softwares disponíveis no mercado possa ter desenvolvido novas funcionalidades que, na ocasião em que foram feitas essas migrações, ainda não estavam disponíveis para estas bibliotecas; ou até mesmo que a equipe de profissionais tenha sofrido baixa em seus integrantes. Esse tema merece posterior aprofundamento de pesquisa.

De um modo geral, a opção dos respondentes sobre sistemas considerados de qualidade para uso em bibliotecas, a pesquisa detectou três alternativas. Por ordem de preferência, as indicações recaíram sobre os sistemas: Pergamum (SPp), Sophia (SPp) e Koha (SLv), este último desde que exista profissional de TI na equipe da biblioteca.

\section{KOHA COMO POSSIBILIDADE NA GESTÃO DOS SERVIÇOS DA BIBLIOTECA DO NIB/CBPF}

Estudos e pesquisas realizados desde meados de 2019, incluindo essa pesquisa exploratória, possibilitaram a seleção de três SLvs para análise. São eles: Koha, BibLivre e PHL. Dentre eles, a equipe do NIB identificou o Koha como 
sendo o mais adequado à biblioteca e o que possui recursos compatíveis aos oferecidos pelo SPp utilizado atualmente.

O Koha possui um pacote de gerenciamento de informação que atende às necessidades básicas de qualquer biblioteca, com oportunidade de expansão de serviços. Ele contempla os módulos de: circulação de materiais, catalogação de fontes monográficas e seriadas, controle de aquisição de fontes de informação, emissão de relatórios de gestão e de divulgação de informação e controle dos usuários. Possui um OPAC com recursos adequados à nova realidade do NIB, além de integrar uma comunidade internacional usuária em constante atividade.

Apesar de sua repercussão ainda ser tímida aqui no Brasil, cerca de 8 instituições identificadas até o momento, em outros países como Portugal já atinge um patamar de mais de 40 instituições usuárias entre autarquias federais, rede escolar, universidades e cursos técnicos, dentre outros tipos de organizações. Em Portugal o uso do Koha em 2017 comemorou 10 anos, com muitos relatos de experiências positivas na CONFERÊNCIA 10 ANOS DO KOHA EM PORTUGAL (2017) ${ }^{4}$. No Brasil já temos alguns relatos sobre este sistema. O Instituto Brasileiro de Informação em Ciência e Tecnologia (IBICT) tem fomentado e incentivado a utilização do Koha no Brasil. Em 2016 apresentou um estudo no Seminário Brasileiro de Bibliotecas Universitárias (SNBU), identificando o Koha como:

[...] uma opção viável às bibliotecas que desejam aderir ao uso de software livre, sem a perda de funcionalidades, garantindo integração com outros sistemas e correspondendo as necessidades de vários tipos de bibliotecas. Dessa forma, o Koha mostra-se um software livre capaz de assegurar custobenefício para as instituições e seus bibliotecários. (SCHIESSL; JESUS; MACÊDO, SHINTAKU, 2016, p. 2)

Aqui no Brasil destacam-se quatro trabalhos, um sobre a experiência com uso do Koha nas bibliotecas públicas de São Bernardo do Campo, SP (FERNANDEZ, 2013) e mais três trabalhos sobre a experiência do Colégio Pedro

\footnotetext{
${ }^{4}$ Detalhes sobre o evento em: https://www.ipl.pt/iplisboa/comunicacao/noticias/koha-softwareque-revolucionou-rede-de-bibliotecas-celebra-10-anos-em. e sobre o programa do evento em: https://www.ipl.pt/sites/default/files/ficheiros/oradores_programa_confirmados_16maio_2.pdf. Acesso em 20 out. 2019.
} 
II com o Koha. Em 2015 (FIGUEIREDO, 2015) uma análise sobre o sistema, em 2016 (FIGUEIREDO; TERRA, 2016) a importação das bases de dados para o Koha e 2017 (FIGUEIREDO; TOURQUATO, 2017) um relato de experiência sobre o processo pós-implantação. Relatos de processos com êxito, alertam que foi necessário trabalho em equipe e o suporte da equipe de TI como referência fundamental para manutenção e atualização do sistema.

O NIB do CBPF já estruturou uma equipe básica multidisciplinar de especialistas para atuar nesse processo de mudança de sistema e de migração de suas bases de dados do Pergamum para o Koha. Atualmente a equipe é coordenada por um físico do $\mathrm{CBPF}^{5}$, sendo composta por dois bibliotecários, um auxiliar de biblioteca, um profissional TI-desenvolvimento e um de TI-segurança.

Com relação à implantação de um SLv, Almeida, 2009 faz o seguinte comentário:

Um projecto open-source requer uma infraestrutura técnica e social, desde a utilização de ferramentas de trabalho colaborativo à implementação de boas práticas. O open-source apresenta vantagens potenciais para as instituições, nomeadamente nas funcionalidades e flexibilidade do software, na sua estabilidade e segurança, no suporte comercial e no custo real. (ALMEIDA, 2009, p. 51)

Nesta etapa de planejamento para a implantação do Koha no NIB prevêse o cumprimento de ações integradas e coordenadas entre si, sendo executadas e supervisionadas por toda a equipe. Generalizando, prevê-se a execução das seguintes tarefas: testes de qualidade das opções de uso do sistema Koha para a biblioteca do NIB; criação e 'alimentação' de base de teste por módulo do sistema; seleção e migração destas bases de teste por módulo do Pergamum para o Koha; entrada simultânea de dados no Pergamum e no Koha, de forma a oferecer segurança ao desempenho dos bibliotecários no processo de trabalho nos módulos do Koha, em relação aos do Pergamum.

\footnotetext{
${ }^{5}$ Mestre em Física da Matéria Condensada - Ressonância Magnética Nuclear pela Universidade Federal Fluminense (1986), doutorado em Modelagem Computacional pelo Instituto Politécnico da Universidade do Estado do Rio de Janeiro (2007). Atualmente é tecnologista senior do Centro Brasileiro de Pesquisas Físicas - CBPF/MCT e também atua na coordenação de engenharia operacional da RedeRio de Computadores - CEO/RR/FAPERJ. As principais atividades são na área de redes de computadores, computação de alto desempenho e modelagem computacional. ID Lattes: 4527634074254559
} 
Futuramente, com os módulos-teste aprovados, prevê-se migrar integralmente, módulo a módulo, as bases de dados do Pergamum para o Koha, mantendo durante um certo período de tempo os dois sistemas em uso, até que haja total maturidade da equipe sobre a efetividade do Koha para o NIB.

Neste momento, ainda não há cronograma definido para o cumprimento dessas tarefas iniciais de adoção do Koha no NIB. Porém, em todas as ações neste sentido, a equipe de TI estará dando suporte ao processo, desde a implantação, parametrização e teste dos módulos do sistema à migração das bases de dados e manutenção e segurança das informações do sistema no servidor do NIB.

A equipe de trabalho é responsável pelo estudo da tecnologia, a troca de experiências com outras instituições, testes e possíveis inovações que venham a ser propostas para o Koha.

\section{CONSIDERAÇÕES FINAIS}

Por todos os dados de pesquisa levantados até o momento, o Sistema Pergamum é avaliado como um SPp de ótima aceitação no mercado, porém tem com as limitações de um SPp, sendo difícil a customização a cada instituição cliente. Questão essa que tem inviabilizado o sistema em relação às metas do NIB para o atendimento à sua comunidade.

Estudos de investigação sobre sistemas de biblioteca, feitos pela equipe do NIB de 2019 à atualidade, incluindo o resultado dessa pesquisa, sugeriram o SLv Koha como promissor para a gestão dos serviços de bibliotecas. Sua utilização ainda é tímida no Brasil, não permitindo que se tenha muitos relatos de experiência, sejam eles positivos ou não. Por ser um software livre, requer a atenção de profissionais de TI para sua parametrização, implantação e acompanhamento, sem o qual dificultaria finalizar o processo com efetividade. Uma equipe constante, multidisciplinar, integrada e comprometida com um plano de metas, é condição fundamental para fazer o Koha 'acontecer' e se consolidar como o sistema de gestão de informação na biblioteca do NIB.

Quanto ao resultado da pesquisa, é inquestionável que o SPp é o sistema 
que oferece mais facilidades à execução das tarefas de uma biblioteca. Já vem com seus módulos formatados, contando com suporte técnico do fornecedor na instalação, parametrização e catalogação. Comercializa serviço permanente de assistência técnica e atualização das novidades do sistema, cursos e vídeos de atualização, o que ajuda muito o trabalho do bibliotecário.

Questões de customização foram levantadas na pesquisa, mas que não inviabilizam a satisfação dos clientes. Sabe-se que geralmente há escassez de verbas para bibliotecas e, mesmo o sistema sendo pago, é vantagem usar um SPp para a maioria das bibliotecas continuarem a atender a seus usuários. Os motivos são variados, tendendo à carência de pessoal especializado e dificuldade de planejamento de ações em médio e longo prazos.

Já o SLv é uma opção não tão confortável quanto é o SPp. É desafiante. Exige atualização permanente de toda a equipe em todas as fases do processo de trabalho e em todas as novidades incorporadas ao sistema, incluindo ações de TI. Seu uso depende de trabalho em rede de usuários, que favorece 0 intercâmbio e a circulação de novos conhecimentos entre profissionais de instituições variadas. Existe a motivação pelo aperfeiçoamento profissional contínuo do bibliotecário para atender às necessidades específicas. É no compartilhamento de informações técnicas e tecnológicas que surgem as facilidades ao trabalho da biblioteca para criar e dinamizar os serviços que presta. A qualidade está na melhor condição de customizar, agradar e comprometer a quem se utiliza do SLv.

No atual momento do NIB, em que se busca inovação em serviços, o Koha foi aceito por toda a equipe como uma alternativa promissora e desbravadora de novos caminhos. "Ainda não podemos relatar nossa experiência com o software, mas estamos otimistas ...."

\section{REFERÊNCIAS}

ALMEIDA, Bruno Filipe Aguiar Ribeiro de. Avaliação de software em opensource para a gestão da biblioteca UNL no campus de Caparica. Relatório de Estágio apresentado para cumprimento dos requisitos necessários à obtenção do grau de Mestre em Ciências da Informação e da Documentação - 
Área de Especialização em Biblioteconomia realizado sob a orientação científica de Paulo Jorge de Oliveira Leitão e Luís Nuno Espinha da Silveira, 2009.

BRASIL. Instrução Normativa n4, de 11 de setembro de 2014. Disponível em: https://www.gov.br/governodigital/pt-br/legislacao/IN42014Completa.pdf. Acesso em: 20de mar. 2020.

CAFÉ, Lígia; SANTOS, Christophe dos; MACEDO, Flávia. Proposta de um método para escolha de software de automação de bibliotecas. Ci. Inf., v.30, n.2, p.70-79. ago. 2001.

CARREZ, Thierry. Open-source in 2019. Disponível em: https://opensource.org/node/1006

CONFERÊNCIA 10 ANOS DO KOHA EM PORTUGAL (2017). Disponível em: https://www.ipl.pt/iplisboa/comunicacao/noticias/koha-software-que-

revolucionou-rede-de-bibliotecas-celebra-10-anos-em). Acesso em: 22 de abr. 2020.

FERNANDEZ, Rafael Saad. O uso de softwares livres na gestão pública de acervos informacionais: o caso do Koha nas bibliotecas de São Bernardo do Campo. Inf. Inf., Londrina, v. 18, n.2, p. 231 - 248, maio/ago. 2013. Disponível em:

http://www.uel.br/revistas/uel/index.php/informacao/article/view/16174/13099. Acesso em: 02/07/2019. DOI: 10.5433/1981-8920. ISSN: 1981-8920

FIGUEIREDO, Márcia Feijão de. Análise do software Koha no Colégio Pedro II: Um relato de experiência. $\mathbf{R D B C l}$ : Revista Digital de Biblioteconomia e Ciência da Informação, Campinas, SP, v. 13, n. 3, p. 653-665, set. 2015. Disponível em: https://periodicos.sbu.unicamp.br/ojs/index.php/rdbci/article/ view/2125. Acesso em: 28 ago. 2017. doi:http://dx.doi.org/10.20396/rdbci. v13i3.2125

FIGUEIREDO, Márcia Feijão de; TERRA, Isabela Cristina Teles. A implantação do Koha no Colégio Pedro II em quatro atos. Revista ACB, Florianópolis[S.I.], v. 21, n. 1, p. 253-264, mar. 2016. Disponível em: https://revista. acbsc.org.br/racb/article/view/1154 Acesso em: 28 ago. 2017.

FIGUEIREDO, Márcia Feijão; TOURQUATO, Lehy Chung Baik. Cenário pósimplantação do software Koha no Colégio Pedro II. Revista Conhecimento em Ação. Rio de Janeiro, v. 2, n. 2, jul/dez. 2017

INFOWESTER. Software livre, código aberto e software gratuito: as diferenças. Disponível em: https://www.infowester.com/freexopen.php. Acesso em 17 abr. 2020

LIMA, Clóvis Montenegro de; SANTINI, Rose Marie. Produção colaborativa de softwares livres: trabalho e tecnologia na sociedade da informação. Inf. \& 
Soc.:Est., João Pessoa, v.18, n.2, p. 101-110, maio/ago. 2008. Disponível em: https://periodicos.ufpb.br/ojs2/index.php/ies/article/view/1734/2114

O QUE É OPEN SOURCE? Disponível em:

https://canaltech.com.br/produtos/O-que-e-open-source. Acesso em 20 de abr. de 2020.

OLIVEIRA, Klaus Felinto de. Estudo sobre os fatores que influenciam a decisão pela adoção do software livre em instituições públicas.

Dissertação (Mestrado em Administração e Negócios) - Fac. de Administração, Contabilidade e Economia, PUCRS. Orientação: Prof. Leonardo Rocha de Oliveira. Porto Alegre, 2010

PROJETO GNU. Disponível em:

https://www.gnu.org/philosophy/philosophy.html. Acesso em 14 de abr. 2020.

SALES, Luana Farias, SAYÃO, Luís Fernando. Há Futuro para as Bibliotecas de Pesquisa no Ambiente de eScience? Informação \& Tecnologia (ITEC): Marília/João Pessoa, 2(1): 30-52, jan./jul., 2015. Disponível em: https://periodicos.ufpb.br/ojs/index.php/itec/article/view/26029/14677. Acesso em: 02 de abr. 2020.

SILVEIRA, Sérgio Amadeu da. Software livre: a luta pela liberdade do conhecimento. São Paulo: Editora Fundação Perseu Abramo, 2004. - (Coleção Brasil Urgente). (E-book). Disponível em: https://www.ufrgs.br/soft-livreedu/arquivos/amadeu-livro-soft-livre.pdf.

SURVEY MONKEY. Disponível em: https://www.surveymonkey.com/. Acesso em: 15 de jul de 2019.

VIANA, Michelângelo Mazzardo Marques. Uma breve história da automação de bibliotecas universitárias no Brasil e algumas perspectivas futuras. RICl:

R.Ibero-amer. Ci. Inf. Brasília, v. 9, n. 1, p. 43-86, jan./jun.2016. https://www.brapci.inf.br/index.php/res/download/88656

OLIVEIRA, Klaus Felinto de. Estudo sobre os fatores que influenciam a decisão pela adoção do software livre em instituições públicas.

Dissertação (Mestrado em Administração e Negócios) - Fac. de Administração, Contabilidade e Economia, PUCRS. Orientação: Prof. Leonardo Rocha de Oliveira. Porto Alegre, 2010.

SCHIESSL, Ingrid Torres et al. Koha um sistema integrado de gerenciamento de bibliotecas. In: SEMINÁRIO NACIONAL DE BIBLIOTECAS UNIVERSITÁRIAS, 19., 2016, Manaus. Anais [...]. ISSN 2359-6058. Disponível em: https://repositorio.ufba.br/ri/handle/ri/27708. Acesso em: 07 ago. 2019

\section{OPEN-SOURCE SOFTWARE AS AN INNOVATION}




\title{
ALTERNATIVE IN THE MANAGEMENT OF LIBRARY SERVICES: THE NIB EXPERIENCE AT CBPF
}

\begin{abstract}
Introduction: Initial discussing concerning to open source software use as an innovative option to library services. It presents a brief theoretical study regarding the applicability of proprietary and free software in libraries and the result of exploratory research. Goal: To investigate the NIB's library databases system performance, nowadays the Pergamum proprietary system, and to gather information about libraries satisfaction level with their own information systems. The motivation was to identify a system that offers more autonomy to the NIB library than the current one, so that it could be possible to adapt the new system to the emerging needs of the physics community. Methodology: It'd been done two kind of research, a theoretical one which includes a free and a proprietary software, and a exploratory one, to clarify the use of SIGB in brazilian libraries. This study collected surveys from literature, librarians informal contacts and results of an applied research by questionnaire. Results: The option of an open-source solution appears to NIB, although proprietary systems have $100 \%$ acceptance among customers, with some caveats. The three best evaluated free systems were: Koha (26.2\%), BibLivre and PHL (21.05\%, both). Conclusions: Studies carried out in 2019 by NIB team indicate that the Koha system would satisfy the needs for innovation at library services. The plan for the next step of work is developing the databases tests in the current system to study the possibility of migrating data to Koha and also about the operational procedures to provide security for a probably data migration.
\end{abstract}

Descriptors: Library and archival services. Library automation. Open source. Proprietary programs

\section{SOFTWARE LIBRE COMO ALTERNATIVA DE INNOVACIÓN EN LA GESTIÓN DE SERVICIOS DE BIBLIOTECA: LA EXPERIENCIA DEL NIB DEL CBPF}

\section{RESUMEN}

Introducción: El artículo tiene como objetivo discutir el uso de software libre como alternativa de innovación en los servicios bibliotecarios. Es resultado de una de las etapas de planificación del trabajo del equipo del NIB. El contenido presenta un breve estudio teórico sobre la aplicabilidad de softwares propietario y libre en bibliotecas y expone el resultado de la investigación exploratoria. Objetivo: Investigar el desempeño del sistema de gestión de las bases de datos de las bibliotecas, hoy con sistema propietario Pergamum, y el nivel de satisfacción de las bibliotecas con sus sistemas de gestión de la información. La motivación fue identificar un sistema que ofrezca más autonomía que Pergamum, de manera que sea posible adaptar el sistema a las necesidades de la comunidad física. Metodología: Investigaciones teórica sobre software libre y propietario, y exploratoria, para clarificar el uso del SIGB en bibliotecas brasileñas. Relevamiento de datos a partir de investigación bibliográfica, contactos informales y aplicación de cuestionario. Resultados: Surge la opción de una solución de código abierto, a pesar de que los sistemas propietarios tienen una aceptación del $100 \%$ entre los clientes. Los tres sistemas libres mejor evaluados fueron: Koha $(26,2 \%)$, 
BibLivre y PHL (21,05\% ambos). Conclusiones: Estudios realizados por el NIB desde 2019 indican que Koha cubriría las necesidades de innovación en gestión de servicios bibliotecarios. La siguiente etapa de trabajo del NIB prevé la creación de bases de datos de prueba para permitir la implantación de Koha y procedimientos operacionales de seguridad para una posible migración de datos.

Descriptores: Servicios bibliotecários. Automatización de bibliotecas. Programas de software libre. Programas proprietário. 


\section{APÊNDICE A - SOFTWARE LIVRE EM BIBLIOTECAS}

1. Qual o sistema utilizado para a gestão da biblioteca?

2. Qual a motivação para escolha do software?

- Recursos oferecidos ( )

- Gratuidade ( )

3. A migração dos dados foi feita a partir de qual software utilizado anteriormente?

4. Como foi o processo de migração?

- Simples ( )

- Média complexidade ( )

- Complexo ( )

5. A biblioteca possui uma equipe de TI própria?

- $\operatorname{Sim}($ )

- Não ( )

6. Como você define o funcionamento do sistema de forma geral?

- Insatisfatório, não atende as necessidades da biblioteca e usuários ( )

- Satisfatório, atende de forma moderada as necessidades da biblioteca e seus usuários ( )

- Excelente, atende todas as necessidades da biblioteca e seus usuários ( )

7. A biblioteca utiliza todos os recursos oferecidos pelo sistema? Se sua resposta for não, descreva quais os recursos que não são utilizados e porquê.

8. Sua biblioteca possui e-books? Se sua resposta for sim, responda a próxima pergunta, caso seja não pule para a pergunta de número 10.

9. O sistema utilizado permite a gestão de e-books? Se sua resposta for não nos relate como fazem a gestão deste material.

10. Você indicaria outro software para sua instituição? Qual? 


\section{APÊNDICE B - PESQUISA DE SATISFAÇÃO SOBRE O SISTEMA PERGAMUM}

1. Sua instituição encontra-se satisfeita com os serviços oferecidos pela empresa? Sim ( ) Não ( )

2. Existe algum serviço não oferecido pelo Pergamum que você gostaria que fosse disponibilizado?

3. Qual serviço(s) oferecido(s) pelo Pergamum você considera que precisam de melhorias?

4. Há quanto tempo sua instituição utiliza o Sistema Pergamum?

5. Você indicaria outro software para sua instituição?

Recebido em: 10.08 .2020

Aceito em: 18.11 .2020 